\title{
CRIANÇAS DE SANGUE ACERCA DO RITUAL DOS JITONG
}

Bony Braga Schachter (Universidade Fudan, Shanghai)

$O$ artigo discute um importante aspecto da vida religiosa de Taiwan, Hong Kong e Cingapura, o ritual dos jitong, cuja característica mais marcante é a ocorrência da possessão, seguida por dramático ato de autoimolação, aqui explicado como uma espécie de obra de arte, isto é, como algo que envolve projeto e cálculo, e não como manifestação do divino no âmbito humano.

ARTE, RELIGIÃO, HISTÓRIA, JITONG

SCHACHTER, Bony Braga. Crianças de sangue: acerca do ritual dos jitong. Textos escolhidos de cultura e arte populares, Rio de Janeiro, v.9, n.2, p. 41-52, nov. 2012. 


\section{CHILDREN OF BLOOD}

\section{THE JITONG RITUAL}

Bony Braga Schachter (Fudan University, Shanghai)

The article discusses an important aspect of religious life in Taiwan, Hong Kong and Singapore, the Jitong ritual, which has as its most striking feature the occurrence of possession, followed by dramatic acts of self-immolation, here explained as a kind of art work, that is, as something that involves design and planning, and not as a manifestation of the divine in the human realm.

\section{ART, RELIGION, HISTORY.}

SCHACHTER, Bony Braga. Crianças de sangue: acerca do ritual dos jitong. Textos escolhidos de cultura e arte populares, Rio de Janeiro, v.9, n.2, p. 41-52, nov. 2012. 


\section{O JITONG (乩童)}

A religião sempre foi parte significativa da vida cultural chinesa e muitas vezes não apenas uma ferramenta de assimilação de poder político e divino, mas também grande preocupação para os administradores. Não são poucas as revoltas populares que tiveram alguma forma de religiosidade como principal fermento. Pode-se citar, por exemplo, a Revolta dos Turbantes Amarelos, no final da dinastia Han (206 a.C. a 220 d.C.), liderada por Zhang Jue, que prometia curar doenças por meio de talismãs e água sagrada (เü, 2001, p. 134-156). A fundação, durante a dinastia Qing, do Reino Celestial da Suprema Paz (18511864) por parte de Hong Xiuquan, por sua vez, teve no cristianismo um de seus principais temas (เÜ, 2001, p. 675-680). A Lótus Branco, organização religiosa que envolvia ritos de possessão, também está associada a inúmeras revoltas, que teriam ocorrido ao longo de três dinastias sucessivas: Yuan (1271-1368), Ming (1368-1644) e Qing (1644-1911) (เü, 2001, p. 718-730). No entanto, mais do que alimentar revoltas, as religiões sempre envolveram a circulação de muitos valores simbólicos e financeiros. Na China contemporânea, o mercado religioso apresenta inúmeras opções, como o budismo, o taoísmo e o cristianismo. Em áreas como Taiwan e Hong Kong, também se verifica a persistência de certas práticas religiosas quase totalmente extintas na China continental. Tais práticas envolvem ritos de possessão de caráter público. Aqueles que conduzem os ritos e, acredita-se, são possuídos pelos deuses, são chamados de jitong. É justamente nas tensões típicas das trocas financeiras, simbólicas e culturais - enfim, de valores, não no sentido que a ética oferece ao termo, mas sim em seu pleno sentido econômico - que podemos encontrar resposta que justifique a sobrevivência de cultos religiosos de natureza semelhante aos praticados pelos jitong em sociedades que passaram por completo processo de modernização.

Diz-se que os jitong possuem os ossos dos deuses. Situam-se no horizonte de práticas religiosas politeístas, que hoje incluem rico e complexo panteão formado não apenas de deuses taoístas e entidades budistas, como também de seres provenientes de lendas transmitidas oralmente e pela cultura literária, como é o caso de Sun Wukong, o deus-macaco imortalizado no romance Viagem ao Oeste, da dinastia Ming. De modo geral, associam-se os jitong aos chineses hokkien, provenientes de áreas como Fujian e Taiwan. Hoje, estão muito ativos sobretudo em Taiwan, Hong Kong e Cingapura. Nessas áreas não se deve subestimar de maneira alguma a importância que os jitong ainda possuem no cenário religioso. 
São denominados crianças divinas pelo fato de se associar o processo de tornar-se um jitong com a possibilidade de escapar a uma vida curta (KIONG, 1998 , p. 23). Segundo registros orais, o jitong estaria originalmente destinado a morrer ainda jovem, podendo, entretanto, esse mau destino ser evitado mediante uma vida inteira de serviço aos deuses ou a um deus particular que o escolhesse como seu servidor. Muitos relatos fornecem esta trajetória: uma pessoa comum adoece de repente, procurando em vão diversos médicos. Já sem esperanças em relação a qualquer forma de medicina, a pessoa busca num templo um mestre de ritos, que poderá revelar ao enfermo o fato de na verdade ele se encontrar num estádio inicial da posssessão, e que sua doença só será curada caso se converta e adote uma vida dedicada aos deuses (KIONG, 1998, p. 57).

Após a iniciação, o futuro jitong deve passar por uma série de rituais se quiser realmente tornar-se um religioso. Segundo a descrição clássica, o iniciado deve privar-se de álcool, fumo, relações sexuais, alucinógenos e carne por 49 dias (KIONG, 1998, p. 79), período em que também deve ter o mínimo de contato possível com o mundo, não podendo aceitar dinheiro para a realização de qualquer serviço religioso. Após esses 49 dias - e o número 49 parece ter algum elo com o conceito budista de morte e transmigração, segundo o qual 49 dias é o período-limite para que a alma de um falecido tome novo rumo no ciclo transmigratório (QING, 2000, p. 187) - o iniciado participa de um ritual em que ocorre sua primeira incorporação de fato, e é geralmente esse ritual que decide a qual divindade ele deverá ofertar uma vida inteira de serviços religiosos.

Um grande número de jitong exerce a religião como atividade profissional, cobrando pelos serviços que oferece, serviços que prometem soluções rápidas para problemas reais enfrentados cotidianamente por qualquer pessoa. É como se o deus ao qual o jitong serve fosse capaz de realizar qualquer desejo de uma pessoa. Eles se propõem a solucionar problemas como falta de dinheiro, desemprego, doenças terminais, insatisfação com a vida amorosa, maridos que possuem amantes, "injustiças" cometidas por vizinhos, desavenças familiares. Além disso, os deuses também podem ajudar em problemas não necessariamente deste mundo: caso alguém se esteja sentindo perseguido por algum fantasma ou o espírito de um parente morto, o jitong pode ajudar realizando serviços de exorcismo (KIONG, 1998, p. 154). Quanto mais clientes um jitong possui maior será a sua credibilidade, mas muitos deles escolherão exercer outra profissão paralela a fim de evitar a má impressão de que estão ganhando dinheiro por meio do culto destinado aos deuses. Uma noite de ritual pode contar com a presença de centenas de fiéis buscando a 
resolução de seus problemas. Esta é uma característica da religião dos jitong: ela não envolve uma narrativa universal e grave, como a do cristianismo. Não há o conceito de deus nem de salvação da alma por meio da fé nesse deus. Se há alguma forma de "salvação" no contexto da religião do jitong, ela tem a ver justamente com a solução de pequenos problemas e a realização de certos desejos, não existindo necessariamente preocupação com o destino da alma, que só adquire importância quando se sente de alguma forma que as almas "do outro mundo" estão prejudicando as pessoas deste mundo. Assim, não se deve nem mesmo esperar dos jitong um grau de sistematização teológica semelhante ao que apresentam os sacerdotes do cristianismo. Antes, é uma religião cujos deuses, mesmo se apresentando em determinada hierarquia (modelada nas relações das diferentes classes sociais da China imperial), na verdade cumprem uma lógica de organização baseada no mito. A razão é algo completamente estranho ao mundo religioso dos jitong, e sua supressão tem no rito sua mais interessante forma.

O ritual de possessão é dramático e envolve uma equipe inteira, podendo ocorrer tanto dentro de templos como em locais públicos, improvisando-se barracões e altares. Procissões religiosas também ocorrem em locais públicos em datas especiais. No momento em que se convidam os deuses, o altar já foi disposto, as oferendas e o incenso já estão colocados na mesa de culto. $\mathrm{O}$ altar é rico em cores e formas, contando com inúmeras imagens, que podem ser tanto impressões quanto esculturas. O altar também comporta vários instrumentos litúrgicos, com os quais o jitong irá conferir bênçãos aos presentes ou imolarse. Quando o altar passou pelos serviços religiosos adequados, uma cadeira especialmente preparada é colocada em sua frente. $O$ jitong senta-se nela, em geral descalço. Caso seja homem, costuma despir a parte superior do corpo. Enquanto isso, seus assistentes reúnem-se a sua volta, cantando e tocando instrumentos musicais, sendo o tambor e os pratos os mais importantes. A música possui ritmo frenético, e os cantos são bastante excitantes. Segundo os religiosos, tais cantos possuem a função de exorcizar o ambiente, afugentando os maus espíritos e preparando o jitong para receber em seu corpo o deus. Os ritos ocorrem aos olhos de todos, e de modo geral não há restrições quanto a filmagens e fotografias.

\section{A POSSESSÃO COMO OBRA DE ARTE}

Antes de prosseguir, cabe afirmar que, sob nenhuma hipótese os jitong considerariam sua atividade uma obra de arte. É meramente por uma questão de retórica e também por necessidade da construção do argumento que 
aqui assim denomino o ápice do ritual. Há obviamente mais motivos para se chamar esses rituais de não arte do que de arte. Uma obra de arte pressupõe projeto e cálculo, certo domínio racional do que está sendo realizado. No ritual de possessão, crê-se que aquele que é possuído não detém qualquer domínio sobre o que faz. Para que se possa entender como se dá a questão da intencionalidade e do domínio de si no contexto dos rituais de possessão dos jitong, porém, é preciso que se descreva esse fenômeno de modo mais detalhado.

Depois que o jitong, descalço e com o torso nu, senta-se na cadeira, como indicado, seus asssistentes começam a entoar cantos de exorcismo. Minutos depois, o jitong começa a fechar os olhos e, com muita frequência, a transpirar copiosamente. Alguns movimentos são recorrentes no transe de quase todos eles: rotações de cabeça, seguidas de inclinação do corpo em direção ao solo. Nesse momento, os assistentes ficam mais apreensivos e preparam-se para segurar o jitong caso realize movimentos muito violentos. Após inclinar-se, o jitong começa a fazer com as mãos e os braços círculos paralelos ao solo. Alguns, antes de inclinar o corpo em direção à terra, apresentam expressão facial típica das pessoas que sentem enjoo e ânsia de vômito. A inclinação no sentido do chão é seguida por fortíssimos espasmos, o corpo do jitong começa a trepidar de modo muito brusco, motivo pelo qual é segurado pelos assistentes, que não podem permitir que ele (ou ela) caia no chão. Segundo relatos, nesse momento o jitong sente uma "força eletromagnética" oriunda dos pés e que o faz começar a pular, como se fosse alçar voo. Nota-se, portanto, que nesse momento dramático da possessão ele ainda está ciente do que se passa. Os jitong afirmam que, quando ocorre a incorporação propriamente dita, eles simplesmente entram num estado mental semelhante ao do sono profundo, não tendo qualquer percepção ou consciência de suas atitudes. Para os adeptos da religião, o momento em que o jitong começa a tremer violentamente é aquele em que o deus está "entrando" em seu corpo. Imagina-se, assim, que o deus é algo que vem de fora e, como um agente físico, é capaz de penetrar o corpo do jitong e causar os espasmos visíveis durante o ritual. Depois que o deus entra no corpo e ali se acomoda, ocorre um último espasmo violento, talvez o mais violento de todos. Nesse instante, alguns jitong se erguem da cadeira e batem na mesa. Outros pulam a uma altura de mais ou menos meio metro e são segurados pelos assistentes. Há aqueles que simplesmente ficam de pé. Quando o deus se instala no corpo do jitong também é comum que ele assuma a postura e o gesto que a imagem do altar representa. 
Neste ponto, vale lembrar que o jitong, se for homem, estará despido da cintura para cima. Alguns mostram interessantes tatuagens que, declaram, são capazes de conferir uma espécie de proteção especial ao portador. O jitong ficará de pé e estático até que seus assistentes terminem de vesti-lo com a indumentária característica de seu deus que, assim como a postura e o gesto, é semelhtante à da estátua que pode ser observada no altar. Não apenas as vestimentas do deus e seu gestual são emulados; sua expressão facial também é objeto de cópia por meio de elaboradas maquiagens. Completamente vestido com as roupas que o caracterizam, o deus pode dar início aos "trabalhos". A partir de então, o jitong irá falar, andar, gesticular como se fosse o próprio deus.

Caso se leve em conta o discurso dos jitong e seus seguidores, o que ocorre é justamente a presença do deus, e não sua emulação. É com base nessa crença que muitos procuram o jitong em busca de auxílio: espera-se a ajuda de um deus, não deste ou daquele homem ou mulher. Durante a possessão, esse deus que agora habita o jitong se aproximará das pessoas, falando acerca de seu estado de saúde, dando conselhos, distribuindo bênçãos das mais variadas formas. Desse modo, o jitong se transforma em oráculo vivo aos olhos dos fiéis, que não possuem a menor dúvida de que seja realmente um deus quem está a sua frente, e não a alma do homem ou da mulher que outrora habitava aquele corpo. Naturalmente, nem sempre esse oráculo vivo fala com clareza. Não raro é necessária a interferência de um assistente para que as palavras do jitong possuído sejam traduzidas, mas o transe em si não seria suficiente para convencer tantas pessoas de que é realmente um deus que se encontra no domínio daquele frágil corpo humano.

Por esse motivo, no ritual de possessão há um elemento importantíssimo que só ocorre durante o transe e pode ser considerado seu ápice. Esse elemento se destina a dotar o rito de uma força de persuasão que nenhum outro recurso poderia garantir. Não basta que o deus venha, fale com os fiéis, realize gestos considerados mágicos - precisará provar que é de fato um deus. A melhor forma de fazê-lo é pela imolação do corpo do jitong. No ritual, os objetos de sacrifício aos deuses incluem doces, bebidas alcoólicas, carnes de diversos tipos, vegetais, flores, velas, incenso, frutas, chá, tudo disposto de modo bastante harmônico diante do altar. O grande sacrifício, contudo, está por vir: a oferenda predileta do deus é o próprio corpo do jitong, que será submetido aos mais diversos tipos de flagelo em homenagem ao sagrado e para o bem dos devotos. É com o sangue que jorra do corpo do jitong que os pecados (conceito incorporado ao imaginário religioso chinês via budismo) dos fiéis (e dele próprio) serão "lavados". Essa é, sem dúvida, a parte do ritual que mais tem chocado os 

Assumindo-se que não há nenhum deus de fato controlando o corpo do jitong, é legítima a pergunta acerca de como ele é capaz de realizar movimentos tão brutais e perigosos contra si, para a qual, aliás, psicólogos e cientistas dão respostas que tornam o fenômeno compreensível. Supondo que os jitong não estão apenas fingindo, mas que, realmente, conseguem convencer-se de que estão em transe, os movimentos aparentemente realizados fora do âmbito do controle consciente podem ser explicados como a manifestação de um distúrbio mental difícil de ser diagnosticado e que pode variar de acordo com cada caso. De qualquer modo, agir sem o pleno domínio consciente da própria ação é algo que ocorre não só nos rituais de transe, mas também com pessoas que ingeriram grandes quantidades de álcool ou outros tipos de drogas em situações completamente distintas daquela que envolve o ritual. Quem não se lembra da cena recorrente em vários filmes em que a mulher, constrangida por não saber nem mesmo o nome do homem com o qual "dormiu" na noite anterior, pergunta o que de fato teria ocorrido entre eles? Entre o comportamento da mulher ou do homem que mantém relações sexuais com alguém sob efeito de drogas e depois não se lembra (e há muitas coisas além do sexo que se pode fazer nessas circunstâncias e depois esquecer por completo) e o comportamento do jitong que, sob o estímulo dos cantos, das cores do altar, das imagens, estátuas etc. age como um deus e depois não se lembra pode haver algum elo objetivo.

Este, contudo, não é um texto acerca dos mecanismos psicológicos e das implicações médicas do que ocorre no ritual de possessão dos jitong, e cabe agora formular um argumento acerca da relação de tal rito com a arte. Afirmei que a razão é completamente estranha ao mundo dos jitong e sua performance algo que se dá na ordem do mito. Essa afirmação, entretanto, só é verdadeira em parte. Há, sim, no ritual de possessão, um projeto e uma estrutura racionalmente organizados. Ocorre, porém, que essa estrutura é toda ela formada de estímulos sensoriais - táteis, olfativos, sonoros, visuais - e conta com a participação de uma série de outras estruturas muito mais poderosas quando comparadas com a capacidade do indivíduo de determinar por si mesmo o que pensa e deseja: o imaginário religioso local, a língua materna, os valores culturais e simbólicos transmitidos pela arte e pela literatura, mas também pelos veículos de comunicação, como o rádio, a televisão e a internet. Aqui se poderia lançar a hipótese de que o jitong é um indivíduo predisposto a certas patologias mentais e, diante da pressão dos inúmeros sistemas culturais da região em que vive, ele simplesmente reage com a possessão, pois não é raro que a possessão seja descrita como evento que envolve a passividade do 
possuído diante daquilo que o possui, não importando o que seja esse agente ativo. Essa, porém, seria tese de certo modo infundada, que apenas substitui a palavra "deus" - associado então pelo mundo culto como representação remota e destituída de sentido no mundo moderno - pela palavra "cultura" pois, segundo tal hipótese, não é um deus que possui o indivíduo, mas a "cultura". Em ambos os casos, nega-se ao jitong o direito de ser ele próprio um sujeito histórico.

É para não cometer esse tipo de equívoco que prefiro pensar a possessão do jitong como obra de arte. Na verdade não se trata ali apenas de uma explosão dionisíaca em que o princípio apolíneo de individuação é completamente suprimido pelo caos mediante os estímulos sensoriais do rito cooperando com as noções abstratas provenientes da cultura. Antes, a possessão é uma obra calculada e inventada por aquele que será possuído, não no sentindo de que seja uma mentira ou um ato de pura má-fé, mas sim como a expressão genuína de uma forma de religiosidade.

Não há nenhum deus ali. Os deuses cultuados pelos jitong, como todos os outros deuses, incluindo-se obviamente nessa categoria o Deus judaicocristão, são apenas belas criações humanas. $O$ que se faz presente no rito de possessão é o princípio do nascimento do teatro, que ocorre não de maneira passiva, como o espetáculo quer nos fazer crer, mas sim por efetiva escolha dos que estão envolvidos na cena. $\mathrm{O}$ jitong é um protoartista, um protoator. Nos rituais de possessão dos jitong, que ainda ocorrem nos dias de hoje, podemos testemunhar, de certa forma, como nasceu o mundo da arte, o que ocorria antes de se atribuir à imitação não o estatuto de imitação, mas sim de presentificação plena da coisa em si. Mesmo diante do comportamento obssessivo, frenético e dotado de maravilhosa histeria e loucura dos jitong podemos encontrar a ordem e o equilíbrio de um grupo que tem perfeita noção do que está ocorrendo, pois há um limite no ritual que não pode ser superado.

Esse limite é justamente o da simetria e da repetição. Deseja-se que os cânticos, a ordem de execução do rito, os passos utilizados e as palavras proferidas sejam sempre os mesmos, ainda que isso seja uma impossibilidade histórica: a cada geração o ritual será recriado para que atenda às novas demandas do ambiente em que será executado e daqueles que o executam. É, porém, por meio da constante repetição do rito que se terá a certeza de que não é uma criação humana que está sendo apresentada diante de quem vê, mas sim algo com origem em um distante passado. $O$ jitong inverte a lógica com que tudo ocorre e nisso ele confunde seus fiéis e a si mesmo. Ao fim, no entanto, todos manifestam o desejo e a curiosidade de ser enganados ou, para 
usar termo mais suave, envolvidos: o jitong não se apresenta como o criador do espetáculo, mas sim como simples instrumento, o meio, através do qual a força criativa do deus se mostra em toda a sua exuberância. E o interessante é que, quando ele assim age, acaba tomando para si toda a dimensão criativa do que ocorre. A máscara, seja ela de tinta ou de sangue, é a melhor metáfora usada no rito para evidenciar que, de um modo ou de outro, todos sabem que se trata de uma criação profundamente humana.

\section{REFERÊNCIAS BIBLIOGRÁFICAS}

LÜ, Simian. Zhongguo tongshi.Shanghai: Shanghai guji chubanshe, 2001.

KIONG, Tong Chee. Tangki Yishi. Tainan: Tainan chubanshe, 1998.

QING, Xitai. Zhongguo daojiao shi. Jiangsua: Editora do Povo de Jiangsu, 2000.

Bony Braga Schachter é bacharel e mestre em história da arte pelo Instituto de Artes da Uerj. Estudou chinês moderno e clássico na Universidade Normal de Nanjing. Atualmente é doutorando do Departamento de História da Universidade Fudan, em Shanghai, onde desenvolve pesquisa com bolsa concedida pelo China Scholarship Council. 